\title{
Analysis of Saliva and Serum of Normal and Anomalies Pregnant Women - Folic Acid Deficiency using FTIR Spectroscopy
}

\author{
R. Raziya Sultana ${ }^{1 *}$, S. N. Zafarullah ${ }^{2}$ and N. Hephzibah Kirubamani ${ }^{3}$ \\ 'Deptartment of Physics, Justice Basheer Ahmed Sayeed College for Women, Chennai-600018, India; \\ saalimraziya@gmail.com \\ 2Department of Physics, Easwari Engineering College, Chennai-600089, India; snzafarullah@yahoo.co.in \\ ${ }^{3}$ Saveetha Medical College, Saveetha Nagar Thandalam, Irrungattukottai, Kanchipuram-602105, India; \\ hepsi1002@yahoo.co.in
}

\begin{abstract}
This study is an attempt to evaluate and compare the spectral difference in saliva and serum between healthy pregnant women and anomalies pregnant women due to folic acid deficiency, using Fourier Transform Infrared Spectroscopy. Folic acid is required for the development of a healthy fetus and plays an important role in the development of the fetus spinal cord and brain. The present work is to study the folic acid deficiency in pregnancy-Anomalies (open neural defect) and compare the results with the normal healthy pregnant women. The results showed that there is a significant difference between the folic acid of healthy pregnant and anomalies (open neural defect) in pregnant women both in saliva and serum sample. From the spectral study, the intensity ratio parameters $\mathrm{R}_{1}\left(\mathrm{I}_{1338} / \mathrm{I}_{3415}\right) \mathrm{R}_{2}\left(\mathrm{I}_{3546} / \mathrm{I}_{1636}\right) \mathrm{R}_{3}\left(\mathrm{I}_{2854} / \mathrm{I}_{3415}\right) \mathrm{R}_{4}\left(\mathrm{I}_{1743} / \mathrm{I}_{3546}\right)$ $\mathrm{R}_{5}\left(\mathrm{I}_{1482} / \mathrm{I}_{1511}\right) \mathrm{R}_{6}\left(\mathrm{I}_{1482} / \mathrm{I}_{1696}\right) \mathrm{R}_{7}\left(\mathrm{I}_{1135} / \mathrm{I}_{1607}\right) \mathrm{R}_{8}\left(\mathrm{I}_{2927} / \mathrm{I}_{1607}\right) \mathrm{R}_{9}\left(\mathrm{I}_{2927} / \mathrm{I}_{1604}\right) \mathrm{R}_{10}\left(\mathrm{I}_{1492} / \mathrm{I}_{1511}\right)$ have been introduced and computed. The outcome of the results shows that FTIR can be used in the qualitative and quantitative investigation of biological fluids to distinguish sample sets from healthy and diseased groups. The internal standard method is adopted in characterizing the samples quantitatively.
\end{abstract}

Keywords: Folic Acid Deficiency, FTIR, Pregnant Women, Saliva

\section{Introduction}

Historically, salivary analyses of female sex hormones were used for fertility and pregnancy monitoring ${ }^{1-3}$. Changes in salivary pattern in normal pregnant women in each trimester have been compared using FTIR spectroscopy both qualitatively and quantitatively ${ }^{4}$. However, recent findings indicate that these assays may be useful beyond the study of reproductive concerns. There is evidence that during pregnancy there are changes and fluctuations in hormone level in normal pregnancy. In certain problems with the fetus during complications of pregnancy, frequent serum sampling for hormone analysis is invasive, inconvenient, and requires skilled personnel to draw samples. However, whole saliva provides an excellent specimen for monitoring the hormone levels. Fourier Transform Infrared spectroscopy (FT-IR) is used to characterize the chemical and structural composition of human saliva of the pregnant women. All the molecules can be excited to higher vibration states using light at specific wavelengths which correspond to the frequency of excited vibration modes. This information can be used to map the absorption positions and assist to identify the chemical properties of the tissue. FT-IR spectroscopy can provide highly sensitive, unique infrared chemical fingerprints of specimens, which can yield new insights into positional changes in saliva of pregnant women.

A key advantage of FT-IR is that it is a quick, nonmanipulative and non-destructive test which can identify

*Author for correspondence 
a wide range of chemical targets. Saliva, like blood, contains protein and nucleic acid molecules which are very large and complex that reflects the physiological status. Essential folate intake during the preconception period, which is the right time before and after a woman becomes pregnant and it assist to protect against a numeral congenital malformations, including neural tube defects which are the most notable birth defects that occur from folate deficiency ${ }^{5}$. Neural tube defects cause critical abnormalities of the central nervous system that acquire in babies during the first few weeks of pregnancy terminating in malformations of the spine, skull, and brain. The most normal neural tube defects are spina bifida and anencephaly. The risk of neural tube defects is reduced in a significant manner when additive folic acid is devouring in addition to a healthy diet before conception and during the first month after conception ${ }^{6,7}$. folic acid supplements has also been shown to reduce the risk of congenital heart defects, cleft lips ${ }^{8}$ limb defects, and urinary tract anomalies. Deficiency of folate during pregnancy may also raise the risk of preterm delivery, spontaneous abortion, infant low birth weight and fetal growth retardation and pregnancy complications, such as placental abruption and pre-eclampsia ${ }^{10}$. Supplementation with Folic acid may also protect the fetus against disease when the mother is battling a disease or taking medications or smoking during pregnancy ${ }^{11}$. It involves oocyte maturation, implantation, placentation, including the general effects of folic acid and pregnancy. Therefore, it is necessary to receive sufficient amounts through the diet to avoid subfertility ${ }^{12}$. There is a development through worldwide that prenatal high folic acid in view of low vitamin B12 resulting in epigenetic changes in the unborn predisposing them to metabolic syndromes, central adiposity and adult diseases such as Type 2 diabetes $^{13}$. In addition, another active area of research and concern is that either much more or too little folic acid in utero affects epigenetic changes to the brain resulting to autism spectrum disorders ${ }^{14,15}$. A salivary test is safer than using serum. The noninvasive collection approach greatly increase their willingness to undergo health inspections, it reduces discomfort, anxiety and monitor their general health over time and helps to diagnose morbidities in the early stage.

Using a simple and effective assay, salivary diagnostics plays an important role in routine health monitoring the early detection of disease ${ }^{16}$. In mid IR spectroscopy, the pure folic acid is characterized with hydroxyl stretching, $\mathrm{NH}$-stretching vibrations, $\mathrm{C}=\mathrm{O}$ bond stretching vibration of carboxyl group, and $\mathrm{C}=\mathrm{O}$ bond stretching vibration of $-\mathrm{CONH}_{2}$ group and $\mathrm{NH}$ - bending vibration ${ }^{17}$. A connection has also been confirmed between neural tube defects in humans and defective folate metabolism ${ }^{18,19}$. On the other hand, an association has been described between neural tube defects.

\section{Materials and Methods}

Saliva samples were collected from normal healthy and open neural anomalies pregnant women subjects from Rajendren Hospital Chennai, who were admitted to hospital for a routine checkup. The samples of saliva were collected from age group 25-30 years. In the present work, using FT-IR analysis folic acid has been chosen and the intensity ratio parameters were calculated. All the sampling procedures were performed between 12.30 to $01.30 \mathrm{pm}$. The Spectral measurements using FT-IR of all the samples were carried out at Sophisticated Analytical Instrumentation Facility IIT, Madras, Chennai-36, using Spectrum-One Perkin-Elmer FT-IR Spectrophotometer. 10 samples were used in each category for spectral exploration. The spectra are recorded in the mid infrared region of 4000-400 cm-in the absorption mode. On thallium bromide crystal window, $50 \mu \mathrm{L}$ of each solution was evenly spread out. To eradicate the stray absorption bands due to water, the samples were air dried for water evaporation and holder is mounted in the sample window of the spectrometer. The spectrometer is well equipped with a globar source, $\mathrm{KBr}$ beam splitter and DTGS cooled detector. 32 scans are co added with a spectral resolution of $1 \mathrm{~cm}^{-1}$ and the sampling window is scanned as the background. To acquire identical area under the curve, all the spectra were baseline corrected and normalized.

\section{Statistical Analysis}

Analysis of variance was implemented to identify the spectral variations that were statistically significant. The $\mathrm{t}$-test is one of the most rapid procedures for classification of biological data. In the current study, the t-tests were used to differentiate certain regions of the FT-IR spectra of the examined healthy saliva and serum samples of healthy pregnant women and saliva, serum samples of anomalies pregnant women. For entire spectrum from 400 to $4000 \mathrm{~cm}^{-1}$, statistical analysis was performed by $\mathrm{t}$-test and it shows the full successful classification to distinguish healthy and anomalies saliva, serum samples of pregnant women. In t-test analysis, considering the mean difference variance of the analysis, the t-test was carried 
out suggesting that the saliva analysis is better compared to the analysis of serum. The absorbance values observed gives a macroscopic value difference as compared to the minute variance observed in the serum analysis using FT-IR. The following are the intensity ratio parameters of saliva and serum samples of healthy and anomalies pregnant women $\mathrm{R}_{1}\left(\mathrm{I}_{1338} / \mathrm{I}_{3415}\right), \mathrm{R}_{2}\left(\mathrm{I}_{3546} / \mathrm{I}_{1636}\right), \mathrm{R}_{3}\left(\mathrm{I}_{2854} / \mathrm{I}_{3415}\right)$, $\mathrm{R}_{4}\left(\mathrm{I}_{1743} / \mathrm{I}_{3546}\right), \mathrm{R}_{5}\left(\mathrm{I}_{1482} / \mathrm{I}_{1511}\right), \mathrm{R}_{6}\left(\mathrm{I}_{1482} / \mathrm{I}_{1696}\right), \mathrm{R}_{7}\left(\mathrm{I}_{1135} / \mathrm{I}_{1607}\right)$, $\mathrm{R}_{8}\left(\mathrm{I}_{2927} / \mathrm{I}_{1607}\right), \mathrm{R}_{9}\left(\mathrm{I}_{2927} / \mathrm{I}_{1604}\right), \mathrm{R}_{10}\left(\mathrm{I}_{1492} / \mathrm{I}_{1511}\right)$. Using FT-IR, saliva and serum samples were analyzed and the results were compared and statistically analyzed using the t-tests. The mean Variance and standard deviation was observed and showed that the intensity ratio of saliva predict a good analysis result as compared to the Serum sample analyzed using FT-IR Spectrum.

The t-test results were analyzed and prove that from the variances of the two samples of the normal and anomalies pregnant women, the Saliva test gives an easier analysis of variance for identification of the anomalies as reviewed through the statistical t-test.

The mean value observed through ' $t$ ' distribution at confidence interval of $95 \%$ shows that the saliva mean is more appropriate for analysis of anomalies as compared to serum analysis through the comparison of intensity ratio parameters. The calculation of confidence intervals and significance tests, values of df associated with the unequal variance condition are rounded to the nearest integer.

This test is used for correlating the means of two samples, even if they have unequal numbers of replicates. In simple terms, comparing the actual difference between two means in relation to the variation in the data expressed as the standard deviation of the difference between the means using the t-test. Statistical tests allow for making statements with a higher degree of precision, but cannot actually proving or disproving anything. Significant results at the $95 \%$ probability level make perfect data, which is good enough to support a conclusion with $95 \%$ confidence (but there is a 1 in 20 chance of being wrong). In Biological work, to maintain and accepts this level of significance as being reasonable.

\begin{tabular}{lclr}
\hline \multicolumn{2}{c}{ Saliva Analysis } & \multicolumn{2}{c}{ Serum Analysis } \\
\hline $\begin{array}{l}\text { Mean difference of } \\
\text { absorbance values }\end{array}$ & 0.568 & $\begin{array}{l}\text { Mean Difference } \\
\text { of absorbance } \\
\text { values }\end{array}$ & 0.054 \\
Standard Deviation & 0.19458 & $\begin{array}{l}\text { Standard } \\
\text { Deviation }\end{array}$ & 0.02319 \\
Standard Error & 0.06153 & Standard Error & 0.00733 \\
\hline
\end{tabular}

\begin{tabular}{lccc}
\hline & Saliva analysis & Serum analysis & Total \\
\hline $\mathrm{N}$ & 10 & 10 & 20 \\
$\Sigma \mathrm{X}$ & 5.6800000 & 0.5399999 & 6.2200000 \\
$\Sigma \mathrm{X}^{2}$ & 3.5669999 & 0.0340000 & 3.6009999 \\
$\mathrm{SS}$ & 0.3408 & 0.0048 & 1.6666 \\
Mean & 0.568 & 0.054 & 0.311 \\
\hline
\end{tabular}

\begin{tabular}{lllllll}
\hline \multicolumn{5}{c}{ t-test assuming equal Sample Variances } \\
\hline Mean $_{\mathrm{a}}-$ Mean $_{\mathrm{b}}$ & $\mathrm{t}$ & $\mathrm{df}$ & & one-tailed & $<.0001$ \\
0.514 & +8.29 & 18 & $\mathrm{p}$ & two-tailed & $<.0001$ \\
\hline
\end{tabular}

\begin{tabular}{lccc}
\hline \multicolumn{4}{c}{ F-Test for the significance of the difference between the } \\
variance of the two samples
\end{tabular}

\begin{tabular}{|c|c|c|c|}
\hline \multicolumn{4}{|c|}{ t-test Assuming Unequal Sample Variances } \\
\hline Mean $_{\mathrm{a}}-$ Mean $_{\mathrm{b}}$ & df & one-tailed & $<.0001$ \\
\hline 0.514 & 9.26 & two-tailed & $<.0001$ \\
\hline & \multicolumn{3}{|c|}{ Confidence Intervals } \\
\hline & Observed & 0.95 & 0.99 \\
\hline Mean $_{a}$ & 0.568 & 0.1391 & 0.2 \\
\hline Mean $_{b}$ & 0.054 & 0.0166 & 0.0238 \\
\hline $\begin{array}{l}\text { Mean }_{\mathrm{a}}-\text { Mean }_{\mathrm{b}} \\
\text { [Assuming equal sample variances] }\end{array}$ & 0.514 & 0.1301 & 0.1785 \\
\hline $\begin{array}{l}\text { Mean }_{\mathrm{a}}-\text { Mean }_{\mathrm{b}} \\
\text { [Assuming unequal sample variances] }\end{array}$ & 0.514 & 0.14 & 0.2014 \\
\hline & \multicolumn{3}{|c|}{ Independent Samples } \\
\hline \multicolumn{4}{|l|}{ Options consider } \\
\hline $\begin{array}{l}\text { One sample analysis } \\
\text { Equal variance } \\
\text { Confidence intervals } \\
\text { Mean 1: } 0.568 \\
\text { Mean 2: } 0.054 \\
\text { Std Dev.1: } 0.19458 \\
\text { Std Dev.2: } 0.00733\end{array}$ & \multicolumn{3}{|c|}{$\begin{array}{l}\text { Two numbers of cases given. } \\
\text { Mean } 1 \text { eq: } 0.568 ; \text { mean } 2 \text { eq: } 0.054 \\
\text { Population standard deviation } \\
\text { estimated using sample } \\
\text { T-distribution used } \\
\text { Difference between means: } \\
0.514 \text { se }=0.0024 \\
95 \% \text { CI of difference: } \\
0.5092<0.514<0.5188 \text { (Wald) } \\
\mathrm{t}=210.4 ; \mathrm{df}=9 ; \mathrm{p}=1\end{array}$} \\
\hline
\end{tabular}

\section{Results and Discussion}

The FT-IR spectra of saliva and the serum samples of normal and anomalies pregnant women show the corresponding 
absorption bands in their specific regions qualitatively. But quantitatively there is a considerable spectral difference between the saliva of normal and anomalies pregnant women and the serum of normal and anomalies pregnant women. The absorbance is directly proportional to the concentration. Hence the serum and saliva samples of normal and anomalies pregnant women are analyzed quantitatively by calculating the intensity ratio among the absorption peaks. The spectral region $3600-3000 \mathrm{~cm}^{-1}$ comprises of $\mathrm{C}-\mathrm{H}, \mathrm{O}-\mathrm{H}$ and $\mathrm{N}-\mathrm{H}$ stretching vibrations of the proteins. Intermolecular hydrogen bonding increases as the concentration of the solution increases and additional bands start to appear at decrease in frequency and the region $3550-3200 \mathrm{~cm}^{-1}$ is at the expense of the "free" hydroxyl band ${ }^{20}$. It is observed in most of the spectra that the vibrations across from $\mathrm{N}-\mathrm{H}$ stretching vibration and $\mathrm{O}-\mathrm{H}$ stretching vibrations got merged and showed a single and broad curve in this region. The region around $3500-2800 \mathrm{~cm}^{-1}$ is due to cholesterol, Phospholipids and creatine and stretching vibrations of $\mathrm{CH} 2$ and $\mathrm{CH} 3$ of phospholipids, cholesterol and creatine $^{21}$. The asymmetric and symmetric stretching C-H vibrations of methyl and methylene group are found to be present around $2930-2875 \mathrm{~cm}^{-122}$. The band at (2933$2923 \mathrm{~cm}^{-1}$ ) is due to $\mathrm{C}-\mathrm{H}$ stretching bands in malignant tissue $^{23}$. The absorption band near (1820-1670 $\left.\mathrm{cm}^{-1}\right)$ is due to $\mathrm{C}=\mathrm{O}$ stretch is strong and it is the stretching mode of lipids ${ }^{24}$ and the band at $1636 \mathrm{~cm}^{-1}$ is due to $\mathrm{C}=\mathrm{C}$ aromatic stretching (vibrational mode). The prominent peak observed at $1697 \mathrm{~cm}^{-1}$ for $\mathrm{C}=\mathrm{O}$ bond stretching vibration of carboxyl group, and it is due to formamide ${ }^{25}$. The peak at $1604 \mathrm{~cm}^{-1}$ is due to $-\mathrm{C}=\mathrm{O}$ stretching of aromatic ring skeletal vibrations ${ }^{26}$. The prominent absorption band around $\left(1300-1000 \mathrm{~cm}^{-1}\right)$ i.e., $\left(1150-1070 \mathrm{~cm}^{-1}\right)$ is due to $\mathrm{C}-\mathrm{O}$ stretch $^{20}$. The absorption peaks occurred in the region of $1480-600 \mathrm{~cm}^{-1}$ is corresponding to amide II band in tissue proteins. Amide II mainly stems from the $\mathrm{C}-\mathrm{N}$ stretching and $\mathrm{C}-\mathrm{N}-\mathrm{H}$ bending vibrations weakly coupled to the $\mathrm{C}=\mathrm{O}$ stretching mode. Aromatic amines display strong $\mathrm{C}-\mathrm{N}$ stretching absorption in the region $1342-1266 \mathrm{~cm}^{-1}$. The absorption appears at higher frequencies than the corresponding absorption of the aliphatic amines because the force constant of the $\mathrm{C}-\mathrm{N}$ bond is increased by resonance with a ring. Results showed that there is a significant difference between the level of serum and saliva samples of normal and anomalies pregnant women of mid IR spectroscopy to all studied groups. A comparison graph between normal and anomalies saliva samples of pregnant women shown in Figure 1. Serum samples of normal and anomalies pregnant women are shown in Figure 2. A striking spectral difference observed between the saliva and the serum samples. A systematic approach has been made using FTIR spectroscopic technique to study the spectral difference between healthy and anomalies pregnant women by using saliva and serum samples and also to find the efficacy of anomalies (open neural tube) defects in the fetus and lack of folic acid present in the pregnant women. The

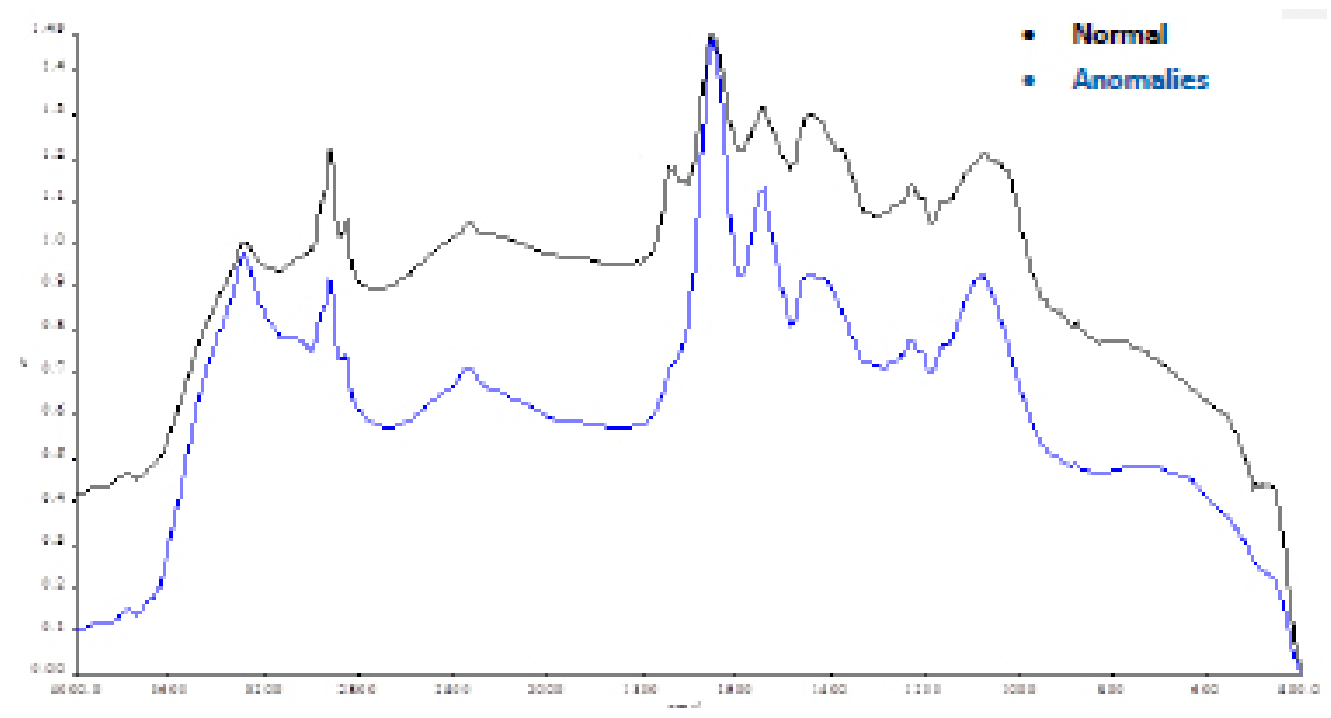

Figure 1. Comparison of saliva of normal and anomalies pregnant women. 
internal standard among the absorption peaks can be calculated. In order to quantify the spectral difference, and ten intensity ratio parameters $\mathrm{R}_{1}\left(\mathrm{I}_{1338} / \mathrm{I}_{3415}\right) \mathrm{R}_{2}\left(\mathrm{I}_{3546} /\right.$ $\left.\mathrm{I}_{1636}\right) \mathrm{R}_{3}\left(\mathrm{I}_{2854} / \mathrm{I}_{3415}\right) \mathrm{R}_{4}\left(\mathrm{I}_{1743} / \mathrm{I}_{3546}\right) \mathrm{R}_{5}\left(\mathrm{I}_{1482} / \mathrm{I}_{1511}\right) \mathrm{R}_{6}\left(\mathrm{I}_{1482} / \mathrm{I}_{1696}\right)$ $\mathrm{R}_{7}\left(\mathrm{I}_{1135} / \mathrm{I}_{1607}\right) \mathrm{R}_{8}\left(\mathrm{I}_{2927} / \mathrm{I}_{1607}\right) \mathrm{R}_{9}\left(\mathrm{I}_{2927} / \mathrm{I}_{1604}\right) \mathrm{R}_{10}\left(\mathrm{I}_{1492} / \mathrm{I}_{1511}\right)$ have been introduced and calculated.

\section{Analysis with Histogram}

The bar diagram shown in Figure 3 and Figure 4 between the intensity ratio parameters and absorbance values were obtained from the FT-IR spectra. The histogram clearly indicates a striking spectral difference between the normal and anomalies pregnant women for both saliva and serum sample.

\section{Conclusion}

With FT-IR spectroscopy, biochemical changes and the spectral difference of both saliva and serum of normal healthy pregnant women and anomalies (open neural defect) in pregnant women are detected and compared. It is concluded that salivary diagnostics possess a high potential to revolutionize the next generation and offer an easy, inexpensive, safe and noninvasive approach for detection of diseased.

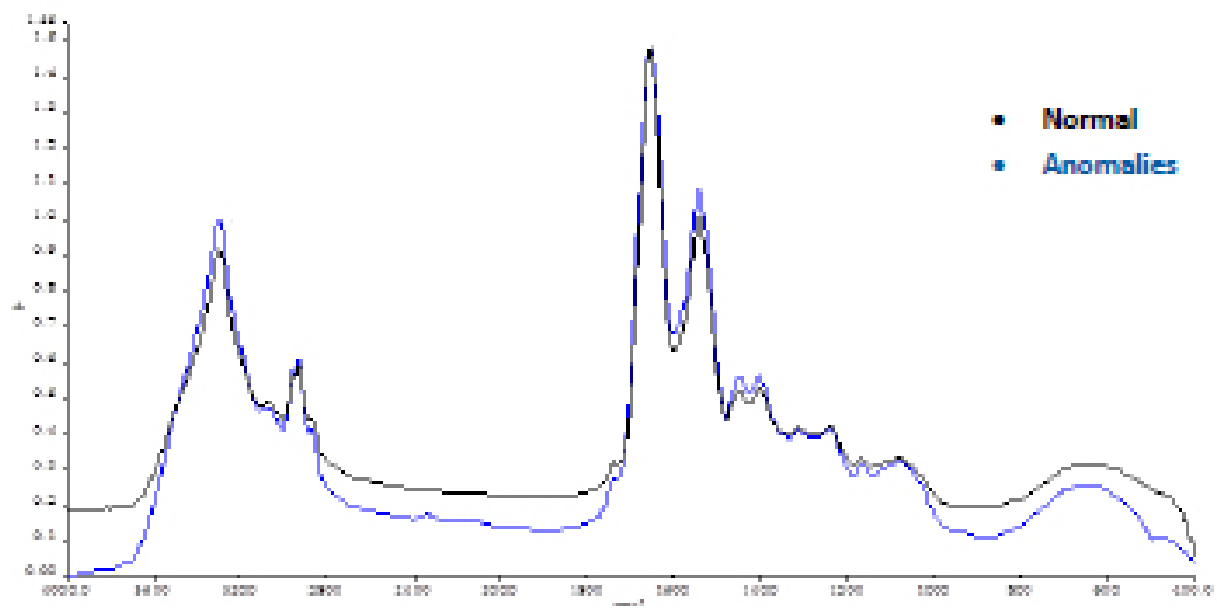

Figure 2. Comparison of serum of normal and anomalies pregnant women.

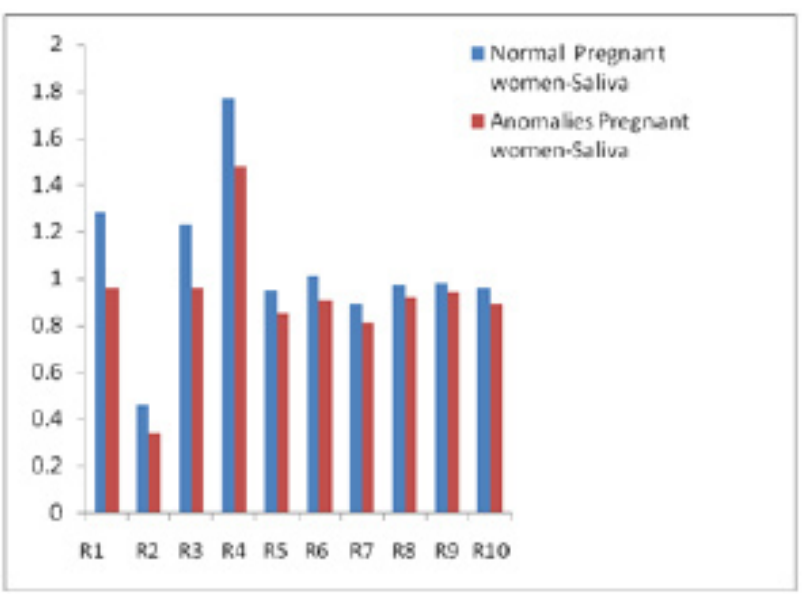

Figure 3. Comparison of intensity ratio parameters of saliva normal pregnant women and anomalies pregnant women.

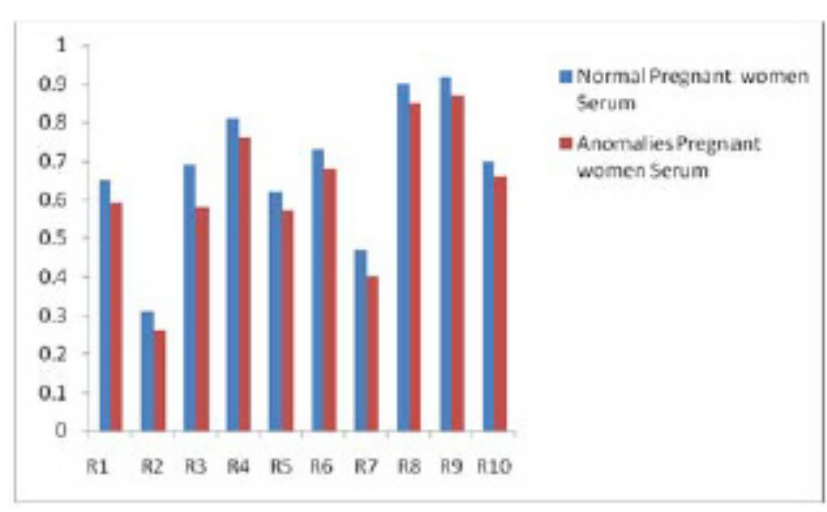

Figure 4. Comparison of intensity ratio parameters of serum normal pregnant women and anomalies pregnant women. 
Table 1. Comparative analysis of saliva and serum of Normal and Anomalies pregnant women

\begin{tabular}{lccccc}
\hline Wavenumber $\left(\mathrm{cm}^{-1}\right)$ & \multicolumn{2}{c}{ Saliva } & & \multicolumn{2}{c}{ Serum } \\
\cline { 2 - 3 } \cline { 5 - 6 } & $\begin{array}{c}\text { Normal Pregnant } \\
\text { women }\end{array}$ & $\begin{array}{c}\text { Anomalies Pregnant } \\
\text { women }\end{array}$ & $\begin{array}{c}\text { Normal Pregnant } \\
\text { women }\end{array}$ & $\begin{array}{c}\text { Anomalies Pregnant } \\
\text { women }\end{array}$ \\
\hline $\mathrm{R}_{1}\left(\mathrm{I}_{1338} / \mathrm{I}_{3415}\right)$ & 1.28 & 0.96 & 0.65 & 0.59 \\
$\mathrm{R}_{2}\left(\mathrm{I}_{3546} / \mathrm{I}_{1636}\right)$ & 0.46 & 0.34 & & 0.31 & 0.26 \\
$\mathrm{R}_{3}\left(\mathrm{I}_{2854} / \mathrm{I}_{3415}\right)$ & 1.23 & 0.96 & & 0.69 & 0.58 \\
$\mathrm{R}_{4}\left(\mathrm{I}_{1743} / \mathrm{I}_{3546}\right)$ & 1.77 & 1.48 & & 0.81 & 0.76 \\
$\mathrm{R}_{5}\left(\mathrm{I}_{1482} / \mathrm{I}_{1511}\right)$ & 0.95 & 0.85 & & 0.62 & 0.57 \\
$\mathrm{R}_{6}\left(\mathrm{I}_{1482} / \mathrm{I}_{1696}\right)$ & 1.01 & 0.91 & & 0.73 & 0.68 \\
$\mathrm{R}_{7}\left(\mathrm{I}_{1135} / \mathrm{I}_{1607}\right)$ & 0.89 & 0.81 & & 0.47 & 0.40 \\
$\mathrm{R}_{8}\left(\mathrm{I}_{2927} / \mathrm{I}_{1607}\right)$ & 0.97 & 0.92 & & 0.90 & 0.85 \\
$\mathrm{R}_{9}\left(\mathrm{I}_{2927} / \mathrm{I}_{1604}\right)$ & 0.98 & 0.94 & & 0.92 & 0.87 \\
$\mathrm{R}_{10}\left(\mathrm{I}_{1492} / \mathrm{I}_{1511}\right)$ & 0.96 & 0.89 & & 0.70 & 0.66 \\
\hline
\end{tabular}

\section{References}

1. Ellison PT. Measurements of salivary progesterone. Ann NY Acad Sci. 1993; 694:161-76.

2. Read GF. Status report on measurement of salivary estrogens and androgens. Ann NY Acad Sci. 1993 Sep 20; 694:146-60.

3. Hofman L. Human saliva as a diagnostic specimen. J Nutr. 2001; 131(5):1621S-5S.

4. Sultana RR, Zafarullah SN, Kirubamani NH. Saliva signature of normal pregnant women in each trimester (ISSN 0974-6846) Indian J. Sci. Technol. 2011 May; 4(5):481-86.

5. Shaw GM, Schaffer D, Velie EM, Morland K, Harris JA. Periconceptional vitamin use, dietary folate, and the occurrence of neural tube defects. Epidemiology. 1995; 6(3):219-26. doi:10.1097/00001648-19950500000005 .

6. Mulinare J, Cordero JF, Erickson JD, Berry RJ. Periconceptional use of multivitamins and the occurrence of neural tube defects. J Am Med Assoc. 1988; 260(21): 3141-5. doi:10.1001/jama.1988.03410210053035.

7. Milunsky A, Jick H, Jick SS, Bruell CL, MacLaughlin DS, Rothman KJ, Willett W. Multivitamin/folic acid supplementation in early pregnancy reduces the prevalence of neural tube defects. J Am Med Assoc. 1989; 262(20): 2847-52. doi:10.1001/jama.262.20.2847.

8. Wilcox AJ, Lie RT, Solvoll K, Taylor J, McConnaughey DR, Abyholm F, Vindenes H, Vollset SE, Drevon CA. Folic acid supplements and risk of facial clefts: national population based case-control study. BMJ. 2007; 334(7591):464. doi:10.1136/bmj.39079.618287.0B.
9. Goh YI, Koren G. Folic acid in pregnancy and fetal outcomes. J Obstet Gynaecol. 2008; 28(1):3-13. doi:10.1080/ 01443610701814195.

10. Scholl TO, Johnson WG. Folic acid: influence on the outcome of pregnancy. Am. J. Clin. Nutr. 2000; 71(5 Suppl):1295S-303S.

11. Jia $\mathrm{ZL}, \mathrm{Li} \mathrm{Y}$, Chen $\mathrm{CH}$, et al. Association among polymorphisms at MYH9, environmental factors, and nonsyndromicorofacial clefts in western China. DNA Cell Biol. 2010; 29(1):25-32. doi:10.1089/dna.2009.0935.

12. Ebisch IM, Thomas CM, Peters WH, Braat DD, SteegersTheunissen RP. The importance of folate, zinc and antioxidants in the pathogenesis and prevention of subfertility. Hum. Reprod. Update. 2007; 13(2):163-74. doi:10.1093/ humupd/dml054. PMID 17099205.

13. Yajnik CS, Deshmukh US. Maternal nutrition, intrauterine programming and consequential risks in the offspring. Rev Endocr Metab Disord. 2008; 9(3):203-11. doi:10.1007/ s11154-008-9087-z.

14. Beard CM, Panser LA, Katusic SK. Is excess folic acid supplementation a risk factor for autism? Med. Hypotheses. 2011; 77(1):15-7. doi:10.1016/j.mehy.2011.03.013.

15. Hamilton J. Folic Acid for Pregnant Mothers Cuts Kids' Autism Risk. NPR; 2013. Available from: http://elireshefmd. com/?paged $=2$

16. Sultana RR, Zafarullah SN, Hephzibah Kirubamani N. Utility of FTIR spectroscopic analysis of saliva of Diabetic pregnant women in each trimester. Indian J. Sci. Technol. 2011 Aug; 4(8):967-70.

17. Zhang J, Rana S, Srivastava R, Misra R. On the chemical synthesis and drug delivery response of folate receptoractivated, polyethylene glycol-functionalized magnetite nanoparticles. ActaBiomater. 2008; 4(1), 40-8. 
18. Wiswell TE, Tuttle DJ, Northam RS, Simonds GR. Major congenital neurologic malformations. A 17-year survey. Am J Dis Child. 1990; 144(1):61-7.

19. Bower C, Miller M, Payne J, Serna P. Promotion of folate for the prevention of neural tube defects: who benefits? Paediatr Perinat Epidemiol. 2005; 19(6):435-444.

20. Silverstein RM, Webster FX, Kiemle D. Spectrometric Identification of Organic Compounds. 7th ed. Hoboken, New Jersey: John Wiley \& Sons; 2005.

21. Huleihel M, Salman A, Erukhimovich V, Ramesh J, Hammody Z, Mordechai S. Novel optical method for study of viral carcinogenesis in vitro. J Biochem Biophys Meth. 2002; 50:111-21.

22. Gunasekaran S, Sankari G. FTIR and UV-visible spectral study on normal and diseased blood samples. Asian J Chem. 2004; 16:1779-86
23. Wu J-G, Xu Y-Z, Sun C-W, Soloway RD, Xu D-F, Wu Q-G, Sun K-H, Weng S-F, Xu G-X. Distinguishing malignant from normal oral tissues using FTIR fiber-optic techniques. Biopolymer. 2001; 62:185-92.

24. Silverstein RM, Bassler GC, Morrill, TC. Spectrometric Identification of Organic Compounds. 4th ed. New York: John Wiley and Sons; 1981.

25. Ragamathunnisa JVR, Padmavathy R. Spectroscopic study on Thiourea and Thiosemicarbazide in Non-aqueous media. IOSR Journal of Applied Physics (IOSR-JAP). 2013; 4(1):05-08.

26. Ke J, Laskar DD, Chen SL. Biodegradation of hardwood lignocellulosics by the western poplar clearwing borer, Paranthrenerobiniae (Hy. Edwards). Biomacromolecules. 2011; 12:1610-20. doi: 10.1021/bm2000132. 